\title{
A comparison of the energy use for different heat transfer fluids in geothermal systems
}

\section{Laurent Gagné-Boisvert}

\author{
Michel Bernier
}

\begin{abstract}
Geothermal systems that operate under $0{ }^{\circ} \mathrm{C}$ must use antifreeze mixtures instead of water to avoid operational problems. This paper examines the energy consumption of the circulating pump and heat pump for various heat transfer fluids used in a residential geothermal system. Propylene glycol, ethanol and methanol solutions at different concentrations are compared. Effects of fluid temperature and viscosity on head losses, borehole thermal resistance and heat pump operation are reviewed. Efficiency curves for currently available circulators are proposed. Annual energy simulations are then performed on a residential GCHP system. Energy consumption (pump and heat pump) is evaluated subhourly based on fluid temperature and properties prevailing during each time step. Results show, as expected, that higher mixture concentrations and higher flow rates lead to higher energy consumption. Methanol with a concentration of $15 \%$ and a $1.5 \mathrm{gpm} /$ ton flow rate provides the best energy performances while ethanol at $30 \%$ with $3 \mathrm{gpm} /$ ton is the worst choice, requiring $16 \% \mathrm{more}$ energy and 525\% more pumping power than for the methanol case. Laminar flow in boreholes appears to be favorable when compared to turbulent flow which leads to relatively high pumping energy consumption. Shorter boreholes piped in parallel decrease energy consumption as well.
\end{abstract}

\section{INTRODUCTION}

A typical residential ground-coupled heat pump (GCHP) system is presented in Figure 1. When such a system operates under $0{ }^{\circ} \mathrm{C}$, an antifreeze mixture must be used to avoid operational problems. Typically, designers select a solution with a freezing point approximately $3^{\circ} \mathrm{C}\left(5^{\circ} \mathrm{F}\right)$ lower than the lowest anticipated temperature (Dow, 2001). Antifreeze solutions affect the performance of the system in many ways. The greater viscosity of these fluids may lead to laminar flow in boreholes with a corresponding increase of the borehole thermal resistance. Pressure drops in the various parts of the system ( $\Delta p_{P i p e}, \Delta p_{\text {Borre }}, \Delta p_{H P}$ and $\Delta p_{\text {Valve }}$ in Figure 1$)$ as well as pumping power $\left(W_{\left.P_{\text {unnp }}\right)}\right)$ are increased when a fluid other than water is used. Moreover, antifreeze mixtures affect heat transfer in the source-side heat exchanger of the heat pump, which decreases heat pump capacity $\left(Q_{C a p}\right)$ and heat pump input power ( $\left.W_{H P}\right)$ but to a lesser extent. The objective of this paper is to study the total energy consumption (pump and heat pump) for various heat transfer fluids typically used in GCHP systems.



Figure 1 Representation of a residential GCHP system.

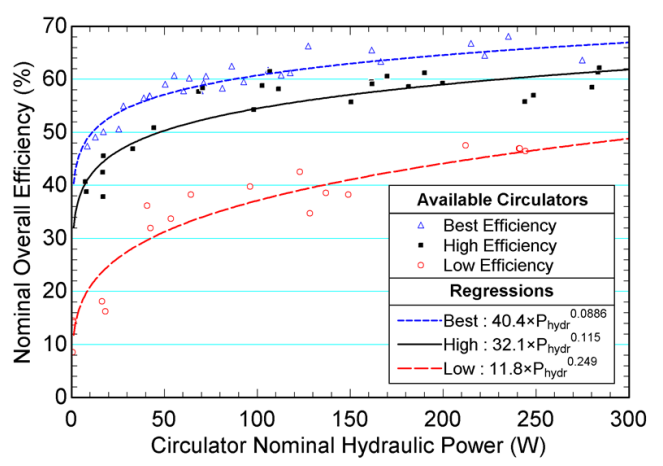

Figure 2 Overall efficiency of available circulators.

Laurent Gagné-Boisvert is a M.A.Sc. student in the Department of Mechanical Engineering, Polytechnique Montreal, Montreal, Quebec, Canada. Michel Bernier (michel.bernier@polymtl.ca) is a professor in the Department of Mechanical Engineering, Polytechnique Montreal, Montreal, Quebec, Canada. 


\section{LITERATURE REVIEW}

Solutions of methanol, ethanol and propylene glycol are often used in GCHP systems. An ASHRAE sponsored study (Heinonen, 1997) concluded that propylene glycol was the best compromise mainly because of its low environmental risk despite the fact that systems with propylene glycol use more energy as noted by Bernier et al. (2005). The toxicity of the inhibitors added to propylene glycol solutions must however be considered.

Pumping energy, which increases with the use of antifreeze, is sometimes considered negligible when compared to the overall energy consumption of a geothermal system. In reality, it can represent up to $45 \%$ of the total energy consumption, even in recent geothermal systems (Liu et al., 2015). Pumping energy is also influenced by the pumping strategy (Kavanaugh and McInerny, 2001). Kavanaugh and Kavanaugh (2012) suggested a maximum ground loop pump power of $10 \mathrm{hp} / 100$ tons $\left(2.1 \mathrm{~kW}_{\text {elec }} / 100 \mathrm{~kW}\right.$ thermal $)$.

A decrement factor $(D F)$ evaluating heat pump convective heat transfer variations due to the use of antifreeze mixtures was developed by Spitler and Jin (2003). The DF corrects the fluid-side heat transfer coefficient initially calculated for water. In a follow-up study, Khan and Spitler (2004) stated that propylene glycol increases system energy consumption by 6 to $7 \%$ compared to ethanol or methanol. In a residential case study, with relatively balanced heating and cooling loads and low antifreeze concentrations, they concluded that typical antifreeze mixtures have similar lifecycle costs while water presents a higher life-cycle cost because a longer borehole is required.

Spitler and Ghelin (2015) challenged the standard industry recommendations to have turbulent flow in the borehole at all times and to maintain head losses in the range of 1 to $3 \mathrm{ft} / 100 \mathrm{ft}$ of pipe (10 to $29 \mathrm{kPa} / 100 \mathrm{~m})$. Their work confirmed Kavanaugh's warning (2011) that high fluid velocities may result in high pumping power with little thermal benefit and even less economic advantage over occasional laminar flow. They also confirmed Mescher's guideline expressed in an ASHRAE Webcast (ASHRAE, 2011) stating that a properly designed bore field should have a head loss $\left(\Delta p_{\text {Borr }}\right)$ of less than $25 \mathrm{ft}(75 \mathrm{kPa})$ with a maximum total system pressure drop of $50 \mathrm{ft}(150 \mathrm{kPa})$.

\section{CIRCULATOR EFFICIENCY}

Circulators are low power pumps typically used to circulate fluid in residential, one-pipe and decentralized GCHP systems. Until recently, circulators had typical efficiency around 20 to 25\% (Kavanaugh and Rafferty, 2015). However, the efficiency of circulators has nearly doubled in recent years (Bidstrup, 2012). Following the methodology used by the COSTIC (2003), an in-house analysis performed for the present study examined the efficiency of 86 commercially available circulators from two manufacturers (Grundfos, 2016 and Salmson, 2016). In each case, the best efficiency point (BEP) was used to extract the nominal overall efficiency at a given nominal hydraulic power. The results of this analysis are shown in Figure 2, which shows the circulator wire-to-water efficiency as a function of the hydraulic power in the 0 to $300 \mathrm{~W}$ range. Circulators are categorized into three classes (Low, High and Best Efficiency) each with its own regression equation. In this work, circulators with the "High" efficiency are used.

\section{HEAT TRANSFER AND REQUIRED HYDRAULIC POWER}

The thermophysical properties used in this work are obtained from the EES software (Klein et al., 2015). For concentration of $30 \%$ by weight $(\mathrm{m} / \mathrm{m})$, this tool gives the following freezing points: $-13{ }^{\circ} \mathrm{C}$ for propylene glycol, -20 ${ }^{\circ} \mathrm{C}$ for ethanol, and $-27{ }^{\circ} \mathrm{C}$ for methanol. The viscosity of antifreeze mixtures is the property having the most notable effect on the energy consumption of geothermal systems. High fluid viscosities lead to low Reynolds numbers and laminar flows in the borehole which tend to decrease the heat transfer coefficients inside borehole pipes. Figure 3a (left) shows the steady-state convective thermal resistance, $R_{\text {onn }}$, and steady-state thermal resistance, $R_{b}$, of a typical borehole using propylene glycol $(30 \% \mathrm{~m} / \mathrm{m})$ and different flow rates (characteristics are given in Table 1). $R_{b}$ is the effective borehole thermal resistance between the fluid and the ground and is the sum of the grout, pipe and convective resistances (Eq. 1). The well-known relations from Hansen and Gnielinski/Petukhov are used to evaluate the convective heat transfer coefficient in borehole pipes for laminar and turbulent flows. 


$$
R_{b}=R_{\text {grout }}+R_{\text {pipe }}+R_{\text {conv }}
$$

As shown in Figure 3a, $R_{\text {conv }}$ increases significantly when the flow becomes laminar at a flow rate smaller than 0.32 $\mathrm{L} / \mathrm{s}$ (for propylene glycol $30 \% \mathrm{~m} / \mathrm{m}$ at $0{ }^{\circ} \mathrm{C}$ ). In turn, this increases the borehole thermal resistance, $\mathrm{R}_{b}$, from 0.12 $\mathrm{mK} / \mathrm{W}$ to $0.20 \mathrm{mK} / \mathrm{W}$. Thus, for a given ground load, the fluid temperature for the laminar case must be lower than for the turbulent case in order to increase the temperature difference between the fluid and the ground. However, as shown by the $P_{\text {bydr }}$ curve on Figure 3a, the required hydraulic power for laminar flow is significantly less than for turbulent flow. The transition to laminar flow also depends on the fluid temperature and pipe diameter. This is shown in Figure 3b where the dip in each curve represents the transition to laminar flow. The linear head loss is about three to four times higher for a $9 \mathrm{gpm}$ flow rate in a 1.25 ” pipe than for a $4.5 \mathrm{gpm}$ in a 1.25 ” pipe.
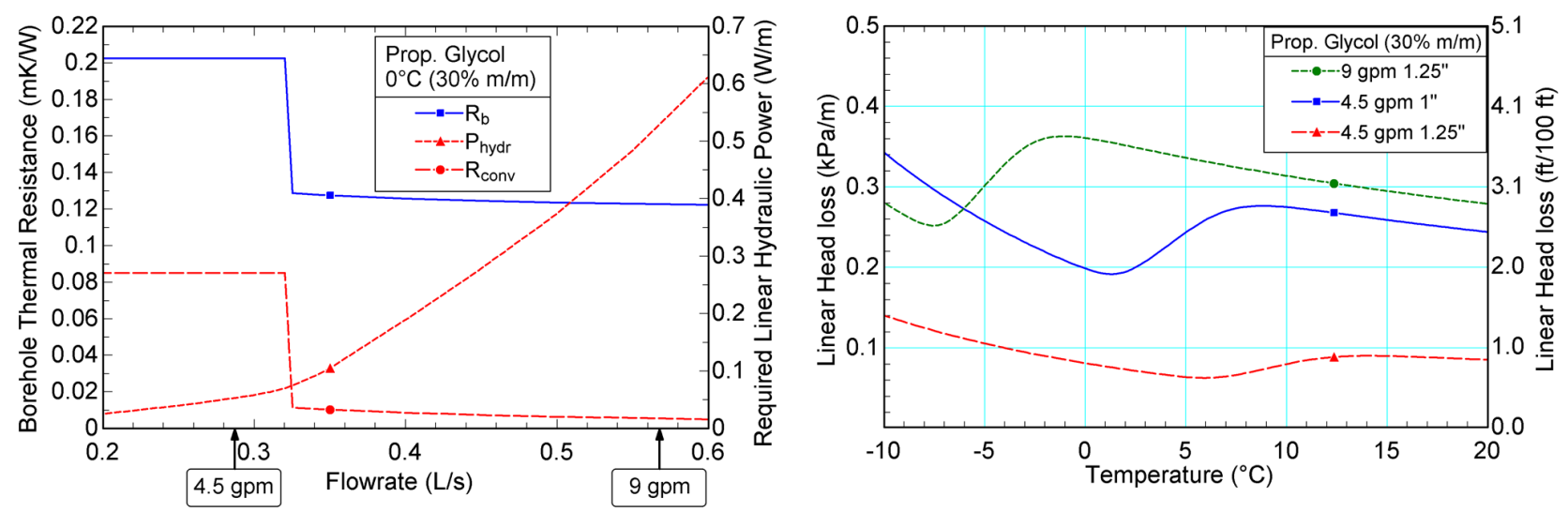

Figure 3a and $\mathbf{b} \quad$ Borehole thermal resistances and required hydraulic power (left) and head loss as a function of temperature (right).

Table 1. Main Characteristics of the Borehole used in this Study

\begin{tabular}{|c|c|c|c|c|}
\hline Parameter & S.I. Value & S.I. Unit & I.P. Value & I.P. Unit \\
\hline Depth & 150 & $\mathrm{~m}$ & 492 & $\mathrm{ft}$ \\
\hline Borehole diameter & 0.15 & $\mathrm{~m}$ & 6 & in \\
\hline Inside pipe radius & 0.013 & $\mathrm{~m}$ & 0.51 & in \\
\hline Outside pipe radius & 0.016 & $\mathrm{~m}$ & 0.63 & in \\
\hline Grout conductivity & 1.5 & $\mathrm{~W} / \mathrm{m} . \mathrm{K}$ & 0.87 & BTU/hr.ft. ${ }^{\circ} \mathrm{F}$ \\
\hline Grout thermal capacity & 3000 & $\mathrm{~kJ} / \mathrm{m}^{3} \cdot \mathrm{K}$ & 44.7 & $\mathrm{BTU} / \mathrm{ft}^{3} .^{\circ} \mathrm{F}$ \\
\hline Ground thermal conductivity & 2.2 & $\mathrm{~W} / \mathrm{m} . \mathrm{K}$ & 1.27 & BTU $/$ hr.ft. ${ }^{\circ} \mathrm{F}$ \\
\hline Ground thermal diffusivity & 0.096 & $\mathrm{~m}^{2} /$ day & 0.94 & $\mathrm{ft}^{2} /$ day \\
\hline Pipe conductivity & 0.42 & $\mathrm{~W} / \mathrm{m} . \mathrm{K}$ & 0.24 & $\mathrm{BTU} / \mathrm{hr} . \mathrm{ft} .{ }^{\circ} \mathrm{F}$ \\
\hline Flow rate & $0.28 / 0.57$ & $\mathrm{~L} / \mathrm{s}$ & $4.5 / 9$ & gpm \\
\hline Borehole resistance $\mathrm{R}_{\mathrm{b}}$ at $0{ }^{\circ} \mathrm{C}(\mathrm{PG} 30 \%)$ & $0.202 / 0.123$ & $\mathrm{~m} . \mathrm{K} / \mathrm{W}$ & $0.350 / 0.213$ & hr.ft. ${ }^{\circ} \mathrm{F} / \mathrm{BTU}$ \\
\hline
\end{tabular}

High fluid viscosities also increase pumping power due to increased pipe friction. Head losses $\left(\Delta p_{P \text { Pipe }}, \Delta p_{\text {Bore }}, \Delta p_{H P}\right.$ and $\left.\Delta p_{\text {Valve }}\right)$ increase as viscosity affects the friction coefficient. With higher head losses, pumping power $W_{P_{\text {unn }}}$ is increased and a larger pump must be used. Increasing flow rate to maintain turbulent flow also increases pumping power. In this work, the Darcy-Weisbach equation is used for pipe head losses and the Churchill equation is used for the friction factor (Eq. 2) as it is suitable for laminar, transient and turbulent flows. A Power Parameter, PP, is also proposed to combine flow rate and pipe diameter (Eq. 3) to allow simple pumping power predictions.

$$
f=8\left(\left(\frac{8}{\mathrm{Re}}\right)^{12}+\left(\left(2.457 \ln \left(\left(\frac{7}{\mathrm{Re}}\right)^{0.9}+0.27 \frac{\varepsilon}{D}\right)\right)^{16}+\left(\frac{37530}{\mathrm{Re}}\right)^{16}\right)^{-1.5}\right)^{1 / 12}
$$




$$
P P=\frac{F_{\text {low }}^{3}}{D_{\text {pipe }}^{5}} \text { (with Flow in gpm and } D_{\text {pipe }} \text { in inches) }
$$

Figure $4 \mathrm{a}$ shows the required linear hydraulic power for $\mathrm{PG} 30 \%$ at $0{ }^{\circ} \mathrm{C}$ as a function of $P P$. Dots represent detailed calculations while the straight line represents a linear regression through the data. The same exercice is performed for different antifreeze solutions with flow rates varying from 2 to $12 \mathrm{gpm}$ and pipe diameters varying from 0.75 to 1.5 ". Linear regressions are then obtained for each fluid (Figure 4b). Each regression presents an absolute RMSE under $0.015 \mathrm{~W} / \mathrm{m}$ and allows an adequate first estimate of pumping power. The well-known criteria of $3 \mathrm{ft} / 100 \mathrm{ft}$ of pipe $(29 \mathrm{kPa} / 100 \mathrm{~m})$ for head loss is also overlayed for 4.5 and 9 gpm flow rates (Kavanaugh and Rafferty, 2015). Figure $4 \mathrm{~b}$ also shows that for a specific flow rate and pipe diameter, pumping power is higher as fluid viscosity increases. Pumping PG $30 \%$ at $0{ }^{\circ} \mathrm{C}$ requires approximately $45 \%$ more power than for water.

The use of Figure $4 \mathrm{~b}$ is best illustrated with an example. A flow of $9 \mathrm{gpm}$ of ethanol $(30 \% \mathrm{~m} / \mathrm{m})$ at $0{ }^{\circ} \mathrm{C}$ through a 1 meter pipe with a diameter of $0.032 \mathrm{~m}\left(1.25^{\prime \prime}\right)$ leads to a value of $P P=239 \mathrm{gpm}^{3} / \mathrm{in}^{5}$ with a corresponding value of $0.18 \mathrm{~W}$ of hydraulic power $(0.19 \mathrm{~W} / \mathrm{m}$ is obtained with a detailed calculation). If the system consists of a $100 \mathrm{~m}$ borehole with $10 \mathrm{~m}$ of connecting pipes to the heat pump (thus a total pipe length of $220 \mathrm{~m}$ ) then $39.6 \mathrm{~W}$ of hydraulic power is required. Pumping this fluid with a 50\% efficient circulator would then require $79 \mathrm{~W}$ of electrical power, $W_{\text {Pump }}$.
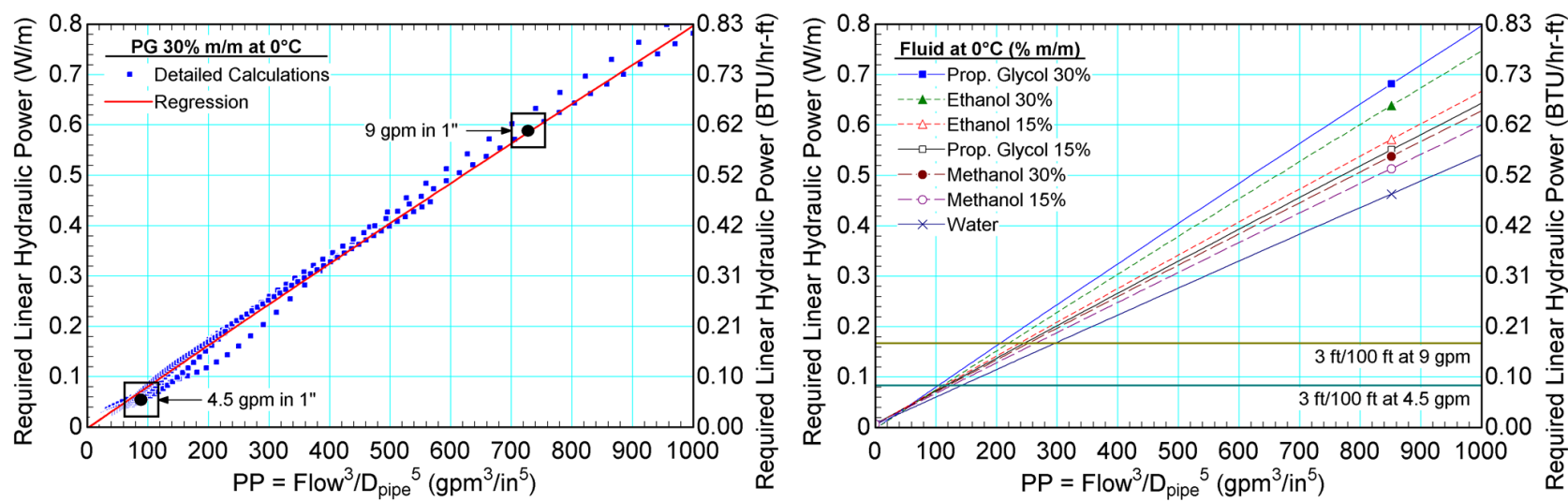

Figure $4 \mathbf{a}$ and $\mathbf{b} \quad$ Required hydraulic power at $0{ }^{\circ} \mathrm{C}$ calculated for PG30\% (left) and predicted for different fluids (right).

Head losses through the source heat exchanger of the heat pump as well as in connecting hoses and valves are also important. Heat pump heat exchanger head loss is typically given by manufacturers and is function of flow rate and inlet fluid temperature. Equation 4, where $\Delta p_{H P}$ is in $\mathrm{kPa}$, Flow in $\mathrm{L} / \mathrm{s}$ and $T_{\text {inHP }}$ in ${ }^{\circ} \mathrm{C}$, is a regression based on a heat pump performance map presenting head loss for several flow and temperature combinations (ClimateMaster, 2012). It is valid for flow ranging from 0.284 to $0.568 \mathrm{~L} / \mathrm{s}(4.5$ to $9 \mathrm{gpm})$ and for inlet temperatures ranging from -1.1 to $48.9^{\circ} \mathrm{C}$ $\left(30\right.$ to $120^{\circ} \mathrm{F}$ ). Valve and hose head losses, combined in one term, $\Delta p_{V a l v e}$, are calculated using flow coefficients used by Kavanaugh and Rafferty (2015): $C_{v}$ equals 25 for the valve and 8 for hoses (based on flows in gpm and a 1 psi (6.9 $\mathrm{kPa}$ ) pressure drop). For 4.5 and 9 gpm flow rates, pressure drops then vary from 0.2 to $0.9 \mathrm{kPa}(0.07$ to $0.3 \mathrm{ft})$ for the valve and from 2.2 to $8.7 \mathrm{kPa}(0.7$ to $2.9 \mathrm{ft})$ for connecting hoses.

$$
\Delta p_{H P}=88.0 \times \text { Flow }-0.179 \times T_{\text {inHP }}-13.3
$$

An antifreeze correction factor for these head losses, $f_{W P D}$, is proposed (Eq. 6). This factor, based on Blasius' equation (Eq. 5), corrects manufacturers' pressure drops, which are based on water. Blasius' equation is valid for low turbulent Reynolds number (White, 2009), which is the case in typical small diameter hoses and heat exchangers. The value of $f_{W P D}$ (Eq. 6) is then the ratio of the pressure drop for the antifreeze solution over the one for water. This factor 
evaluated for different antifreezes and concentrations at $0{ }^{\circ} \mathrm{C}$ was verified against manufacturer's data (ClimateMaster, 2012). As shown in Table 2, the method proposed here (Eq. 5 and 6) is within $2 \%$ of the manufacturer's data for PG. Similar results were obtained for other fluids. $\Delta p_{H P}$ and $\Delta p_{\text {Value }}$ (valve and hoses), calculated for water, are then multiplied by this factor to obtain the actual antifreeze pressure drop, $\Delta p_{a}$.

$$
\begin{aligned}
& \Delta p=0.158 L \rho^{0.75} \mu^{0.25} D^{-1.25} V^{7 / 4} \\
& f_{W P D}=\frac{\Delta p_{a}}{\Delta p_{w}}=\left(\frac{\rho_{a}}{\rho_{w}}\right)^{0.75}\left(\frac{\mu_{a}}{\mu_{w}}\right)^{0.25}
\end{aligned}
$$

Table 2. WPD, capacity and power correction factors for PG

\begin{tabular}{c|cc|ccc|cc}
\hline & \multicolumn{2}{|c|}{ fWPD } & \multicolumn{2}{c|}{$\boldsymbol{f}_{\text {cap, heat }}$} & \multicolumn{2}{c}{$\boldsymbol{f}_{\text {power, heat }}$} \\
\hline \hline Prop. Glycol (\% m/m) & Eq. 6 & Manufacturer & Eq. 9 & Manufacturer & Eq. 9 & Manufacturer \\
\hline \hline $5 \%$ & 1.07 & 1.07 & 0.991 & 0.989 & 0.998 & 0.997 \\
$15 \%$ & 1.20 & 1.21 & 0.972 & 0.968 & 0.993 & 0.990 \\
$25 \%$ & 1.37 & 1.36 & 0.945 & 0.947 & 0.987 & 0.983 \\
\hline
\end{tabular}

\section{HEAT PUMP CAPACITY AND POWER}

The use of antifreeze mixtures also affects heat transfer in the source-side heat exchanger of the heat pump, which has a detrimental effect on heat pump performance. Heat pump heating capacity $Q_{\text {Cap }}$ decreases because of reduced convection in the heat exchanger pipes. Viscosity, density, thermal capacity and conductivity variations reduce capacity, by up to $10 \%$ for a $30 \%$ ethanol solution (ClimateMaster, 2012). Power consumption $W_{H P}$ is also affected and it can decrease by up to $3 \%$ as capacity decreases. However, heat pump energy consumption increases with the use of antifreeze as it must operate for longer periods to meet the load as capacity is reduced.

Capacity and power consumption can be adjusted by correction factors to account for those effects. A capacity correction factor derived from Nguyen's work is used here (2010). This factor, fapauity, (Eq. 9) predicts heat pump capacity variation based on heat pump constants $\left(C_{1}\right.$ and $\left.C_{2}\right)$ and Spitler and Jin's (2003) Decrement Factor (Eq. 7). As shown by Eq. 8 , the two constants are used to evaluate the total heat pump source-side thermal resistance $R_{t} . C_{1}$ stands for the fluid convective resistance initially calculated for water. It is divided by $D F$ to correct the fluid-side convective heat transfer coefficient. $C_{2}$ combines the pipe conductive, the refrigerant convective and the fouling thermal resistances, which are not affected by the choice of the antifreeze solution. $C_{1}$ and $C_{2}$ are back calculated using a pair of capacity correction factors from a manufacturer (ClimateMaster, 2012) with DF calculated for each fluid and each concentration. This leads to a two equations/two unknowns system that can be solved easily. $C_{1}$ and $C_{2}$ equal 1.0 and 16.35, respectively, when calculated using propylene glycol. $C_{1}$ and $C_{2}$ differ slightly when calculated for ethanol and methanol. Fluid specific values of $C_{1}$ and $C_{2}$ are used to predict $f_{\text {capacity }}$ for the simulations performed in this paper.

$$
\begin{gathered}
D F=\frac{h_{a}}{h_{w}}=\left(\frac{\mu_{a}}{\mu_{w}}\right)^{-0.47}\left(\frac{\rho_{a}}{\rho_{w}}\right)^{0.8}\left(\frac{C_{p, a}}{C_{p, w}}\right)^{0.33}\left(\frac{k_{a}}{k_{w}}\right)^{0.67} \\
R_{t}=R_{\text {conv, fluid }}+R_{\text {cond, } p \text { ipe }}+R_{\text {conv }, \text { refrigerant }}+R_{\text {fouling }}=R_{\text {conv }, \text { fluid }}+\Sigma R=\frac{C_{1}}{D F}+C_{2} \\
f_{\text {capacity }}=\frac{R_{t, w}}{R_{t, a}}=\frac{C_{1}+C_{2}}{\frac{C_{1}}{D F}+C_{2}}
\end{gathered}
$$


It also appears that the use of this capacity correction factor proves to be accurate to correct the heat pump power consumption ( $f_{\text {capacity }}$ is replaced by $f_{\text {power }}$ in Eq. 9). The same $D F$ is used but $C_{1}$ and $C_{2}$ are based on the manufacturer's power correction factors. They equal 1.0 and 75.68 , respectively, when calculated using propylene glycol. As shown in Table 2 , the predicted capacity and power correction factors are in good agreement with manufacturer's data.

Finally, there are operational benefits resulting from the use of antifreeze mixtures. Indeed, allowing colder fluid temperatures to the heat pumps $\left(-3{ }^{\circ} \mathrm{C}\right.$ instead of $0{ }^{\circ} \mathrm{C}$ for example) leads to shorter boreholes as the temperature difference between the borehole fluid and the ground is larger. However, this effect might be counterbalanced by increased pumping energy and reduced borehole and heat pump performances. It is thus important to evaluate the overall effects of using a specific antifreeze solution. This is done using annual simulations as shown in the next section.

\section{ANNUAL SIMULATIONS}

Annual simulations using TRNSYS v17 (Klein et al., 2010) are performed to compare the energy consumption of a GCHP system using different antifreeze mixtures (PG, EA and MA) and two flow rates (4.5 and 9 gpm or 1.5 and $3 \mathrm{gpm} /$ ton). A 1-minute time step is used, which is small enough to capture borehole transient effects. The system under study is the one presented in Figure 1. It consists of a 3-ton $(10.5 \mathrm{~kW})$ water-to-air ground-coupled heat pump linked to a $150 \mathrm{~m}$ borehole. The GCHP system provides space heating for a single-family house with enough capacity to avoid the need for an auxiliary heater. The building is simulated in a heating dominated climate (Montreal, Canada) with an annual heating requirement of about $20000 \mathrm{kWh}$. Typical models found in TRNSYS for the building, thermostat, heat pump and pump are used. Heat pump performance is modeled based on a manufacturer's steady-state performance data (ClimateMaster, 2012). The TRCM borehole model from Godefroy and Bernier (2014) is used to model the single U-tube borehole. This experimentally validated model (Godefroy et al., 2016) accounts for fluid and grout thermal capacity, which indirectly affects heat pump performance (Gagné-Boisvert and Bernier, 2016). The main characteristics of the borehole are given in Table 1. The pump is a high efficiency wet rotor circulator. When operating, it is assumed that it provides a constant volumetric flow rate year-round. Pump efficiency is evaluated based on the "High" regression curve presented in Figure 2. Thermophysical properties, correction factors, head losses, and borehole thermal resistance are calculated at each time step.

\section{Comparison results}

Tables 3 and 4 present one-year simulation results while Figure 5 shows the pump power and heat pump inlet temperature evolution over the year. In these tables, pump fraction is the ratio of the pumping energy over the total energy consumption; seasonal performance factor $(S P F)$ is the ratio of the annual heating requirement over the total energy consumption (Nordman and Zottl, 2011); Head ${ }_{\max }$ is the highest total head loss over the year while pump power is the highest required pump power. As illustrated in Figure 5, pumping power decreases by about $10-15 \%$ with higher fluid temperature occurring in summer. $R_{b}$ also varies over the year as fluid temperature fluctuates, as shown by minimum and maximum values in Tables 3 and 4 . These tables show the importance of considering the antifreeze properties and how they influence system operation.

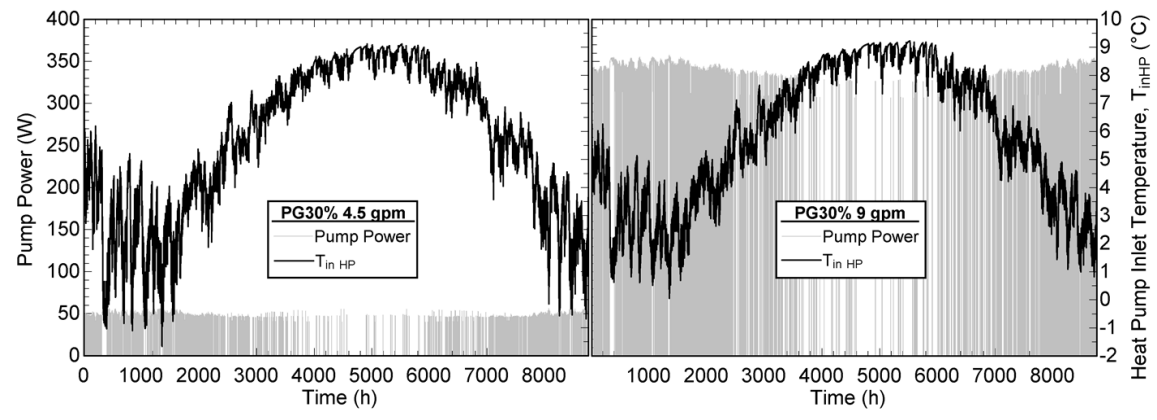

Figure 5a and b Pump power and heat pump inlet temperature for PG30\% at 4.5 (left) and 9 gpm (right) over one year. 
Table 3. Simulation results for $4.5 \mathrm{gpm}$ flow rate

\begin{tabular}{|c|c|c|c|c|c|c|c|c|}
\hline $\begin{array}{c}\text { Fluid } \\
(\% \mathrm{~m} / \mathrm{m})\end{array}$ & $\begin{array}{l}\text { Total } \\
(\mathrm{kWh})\end{array}$ & $\begin{array}{l}\text { Pump } \\
(\mathrm{kWh})\end{array}$ & $\begin{array}{c}\text { Pump Fraction } \\
(\%)\end{array}$ & $\begin{array}{l}\text { SPF } \\
(-)\end{array}$ & $\begin{array}{l}\text { Head }_{\text {max }} \\
(\mathrm{kPa} / \mathrm{ft})\end{array}$ & $\begin{array}{l}\text { Pump power } \\
\text { (W) }\end{array}$ & $\begin{array}{c}\mathbf{R}_{\mathrm{b}, \min / \max } \\
(\mathrm{W} / \mathrm{mK})\end{array}$ & $\begin{array}{l}\mathrm{T}_{\text {inHP, } \min } \\
\left({ }^{\circ} \mathrm{C} /{ }^{\circ} \mathrm{F}\right)\end{array}$ \\
\hline Prop. Glycol 15\% & "6027 & $\overline{126}$ & $2.10 \%$ & 3.36 & 93.8/31.4 & 56.9 & "0.122/0.123 & $0.4 / 33$ \\
\hline Prop. Glycol 30\% & 6286 & 125 & $2.00 \%$ & 3.22 & $99.5 / 33.3$ & 60.0 & $0.127 / 0.204$ & $-1.7 / 29$ \\
\hline Prop. Glycol 40\% & 6545 & 187 & $2.86 \%$ & 3.09 & $155.2 / 51.9$ & 88.9 & $0.212 / 0.213$ & $-1.4 / 29$ \\
\hline Ethanol 15\% & 6114 & 130 & $2.13 \%$ & 3.31 & $92.5 / 30.9$ & 56.2 & $0.123 / 0.125$ & $0.5 / 33$ \\
\hline Ethanol 30\% & 6368 & 120 & $1.88 \%$ & 3.18 & $90.5 / 30.3$ & 55.1 & $0.127 / 0.209$ & $-1.3 / 30$ \\
\hline Methanol 15\% & 6014 & 119 & $1.98 \%$ & 3.36 & $87.3 / 29.2$ & 53.4 & $0.122 / 0.123$ & $0.5 / 33$ \\
\hline Methanol 30\% & 6113 & 127 & $2.07 \%$ & 3.31 & $89.6 / 30.0$ & 54.7 & $0.124 / 0.125$ & $0.8 / 33$ \\
\hline Water & 5878 & 102 & $1.74 \%$ & 3.44 & $75.8 / 25.4$ & 47.1 & $0.120 / 0.121$ & $0.6 / 33$ \\
\hline \multicolumn{9}{|c|}{ Table 4. Simulation results for $9 \mathrm{gpm}$ flow rate } \\
\hline $\begin{array}{c}\text { Fluid } \\
(\% \mathrm{~m} / \mathrm{m})\end{array}$ & $\begin{array}{l}\text { Total } \\
(\mathrm{kWh})\end{array}$ & $\begin{array}{l}\text { Pump } \\
(\mathrm{kWh})\end{array}$ & $\begin{array}{c}\text { Pump Fraction } \\
(\%)\end{array}$ & $\begin{array}{c}\text { SPF } \\
(-)\end{array}$ & $\begin{array}{l}\operatorname{Head}_{\max } \\
(\mathrm{kPa} / \mathrm{ft})\end{array}$ & $\begin{array}{l}\text { Pump power } \\
\text { (W) }\end{array}$ & $\begin{array}{c}\mathbf{R}_{\mathrm{b}, \min / \max } \\
(\mathrm{W} / \mathrm{mK})\end{array}$ & $\begin{array}{l}\mathrm{T}_{\text {inHP, } \min } \\
\left({ }^{\circ} \mathrm{C} /{ }^{\circ} \mathrm{F}\right)\end{array}$ \\
\hline Prop. Glycol 15\% & 6561 & 653 & $10.0 \%$ & 3.08 & $302 / 101$ & 296 & $0.120 / 0.121$ & $-0.1 / 32$ \\
\hline Prop. Glycol 30\% & 6917 & 821 & $11.9 \%$ & 2.93 & $374 / 125$ & 358 & $0.121 / 0.123$ & $0.1 / 32$ \\
\hline Ethanol 15\% & 6670 & 683 & $10.2 \%$ & 3.03 & $313 / 105$ & 305 & $0.120 / 0.121$ & $0.1 / 32$ \\
\hline Ethanol 30\% & 6966 & 786 & $11.3 \%$ & 2.91 & $347 / 116$ & 334 & $0.121 / 0.123$ & $0.4 / 33$ \\
\hline Methanol 15\% & 6519 & 616 & $9.4 \%$ & 3.10 & $282 / 94.3$ & 278 & $0.119 / 0.120$ & $0.0 / 32$ \\
\hline Methanol 30\% & 6647 & 654 & $9.8 \%$ & 3.04 & $292 / 97.7$ & 287 & $0.120 / 0.121$ & $0.3 / 33$ \\
\hline Water & 6324 & 539 & $8.5 \%$ & 3.20 & $250 / 83.6$ & 250 & $0.119 / 0.119$ & $0.0 / 32$ \\
\hline PG 30\% Parallel & 6101 & 265 & $4.3 \%$ & 3.32 & $107.5 / 36.0$ & 119 & $0.126 / 0.204$ & $1.9 / 34$ \\
\hline MA $15 \%$ Parallel & 5865 & 214 & $3.7 \%$ & 3.45 & $86.5 / 28.9$ & 97.8 & $0.122 / 0.123$ & $2.2 / 36$ \\
\hline Water Parallel & 5729 & 187 & $3.3 \%$ & 3.53 & $76.7 / 25.7$ & 88.0 & $0.120 / 0.121$ & $2.3 / 36$ \\
\hline
\end{tabular}

Results show that higher concentrations and higher flow rates increase total energy consumption of the GCHP system. Using methanol with a concentration of $15 \%$ and $4.5 \mathrm{gpm}$ gives the best energy performances with an energy consumption of $6014 \mathrm{kWh}$, a $S P F$ of 3.36 and a maximum pump power of $53.4 \mathrm{~W}$. It is worth mentioning that propylene glycol at $15 \%$ with $4.5 \mathrm{gpm}$ is not recommended for that application considering its $-5{ }^{\circ} \mathrm{C}$ freezing point. Ethanol $30 \%$ with $9 \mathrm{gpm}$ requires $6966 \mathrm{kWh}(+16 \%)$ and $334 \mathrm{~W}$ of pump power $(+525 \%)$ with a SPF of $2.91(-13 \%)$. This case gives the worst energy performance and a bigger and more expensive pump would be required.

For pumping, flow rates of 4.5 and $9 \mathrm{gpm}$ lead to pump fractions of about $2 \%$ and $10 \%$, respectively. Based on an average $8 \mathrm{~kW}$ peak heating load, a pumping grade of A on the Kavanaugh and Rafferty (2015) scale is achieved for all $4.5 \mathrm{gpm}$ cases. A grade of $\mathrm{F}$ is obtained for $9 \mathrm{gpm}$ cases. Higher flow rates and concentrations are responsible for bigger head losses, leading to higher pumping power and energy consumption. It appears that systems with head losses under $100 \mathrm{kPa}(4.5 \mathrm{gpm})$ lead to better overall energy performances than $\sim 300 \mathrm{kPa}(9 \mathrm{gpm})$ cases, which is in line with Mescher's statement presented earlier. Interestingly, for propylene glycol $30 \%$ and ethanol $30 \%$ with $4.5 \mathrm{gpm}$, pumping energy is lower than for cases with a $15 \%$ concentration, which is counterintuitive as these solutions are more viscous. This is because those two cases are in laminar flow around $90 \%$ of the operation time, which leads to lower head losses (Figure 3b). The PG40\% at $4.5 \mathrm{gpm}$ case always operates in laminar flow and presents higher head losses than the PG $30 \%$ case. Its minimum heat pump inlet temperature is also slightly higher because more energy comes from the heat pump compressor and less from the ground.

It is important to note that these three $4.5 \mathrm{gpm}$ laminar cases, with typical laminar $R_{b}$ values and lower loop temperatures, yield lower energy consumption $(-10 \%)$ than the same cases with the fully turbulent 9 gpm flow rate. This is mainly due to the higher pumping requirements. Based on that, a common GCHP system using propylene glycol at $30 \%$ would require less energy if working with $4.5 \mathrm{gpm}$ versus $9 \mathrm{gpm}$, even if the borehole flow is almost always laminar. This confirms Kavanaugh's recommendation. Thus, designers must be aware that the heat transfer advantage of turbulent flows is small compared to the increased pumping energy consumption in GCHP systems. Figures 6a and 6b present a breakdown of peak head losses to help understand flow rate effects on results. Cases with 4.5 and $9 \mathrm{gpm}$ using propylene glycol $30 \%$ are presented. As expected, the various head losses are about four times higher when the flow 
rate is doubled.
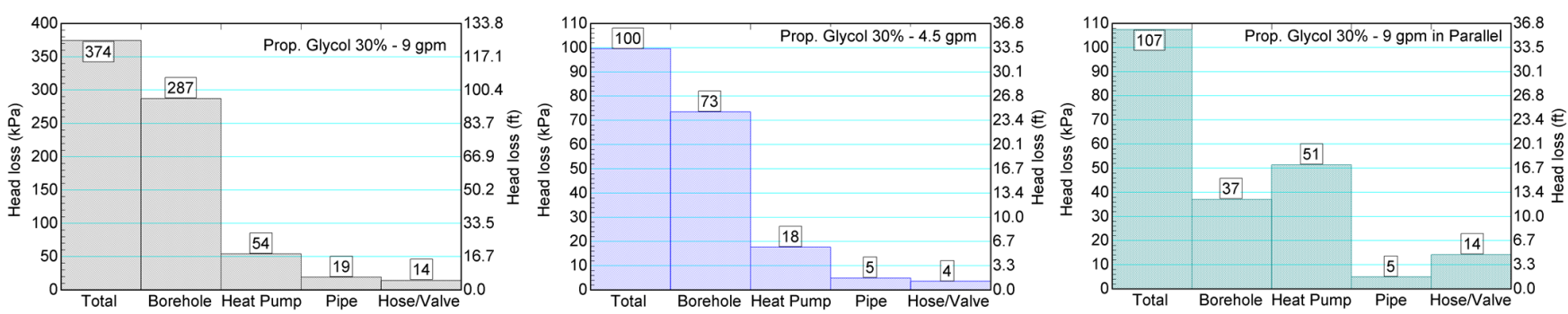

Figure 6a, b and c Breakdown of peak head losses for PG30\% at $4.5 \mathrm{gpm}$ (left), $9 \mathrm{gpm}$ (center) and in parallel (right).

The same simulations are performed without the correction factors $\left(f_{\text {capacity }}, f_{\text {power }}\right.$ and $\left.f_{W P D}\right)$ to assess their importance. In all cases, neglecting correction factors underestimates energy consumption. The extent of the underestimation is higher for higher antifreeze concentrations. Neglecting the capacity and power correction factors underestimates heat pump energy consumption by 2 to $6 \%$, pump consumption by 3 to $9 \%$ and overall energy consumption by 2 to $7 \%$. Neglecting the head loss correction factor (heat pump, hoses and valve) underestimates pump energy consumption by 3 to $8 \%$ and overall energy consumption by 0.1 to $0.7 \%$ as pumping represents 2 to $10 \%$ of the total. Neglecting both factors underestimates pump energy consumption by 6 to $15 \%$ and overall energy consumption by 2 to $7 \%$. Table 5 presents these differences for propylene glycol 15 and $30 \%$ at $9 \mathrm{gpm}$.

Table 5. Effects of correction factors on energy consumption (Propylene Glycol $9 \mathrm{gpm}$ )

\begin{tabular}{l|c|ccc|c|crc}
\hline & Pump & \multicolumn{3}{|c|}{ Without } & \multicolumn{3}{c}{ Total } & \multicolumn{3}{c}{ Without } \\
\hline \hline Fluid $\% \mathrm{~m} / \mathrm{m}$ & $\mathbf{( - )}$ & $\boldsymbol{f}_{\text {cap }}+\boldsymbol{f}_{\text {power }}$ & $\boldsymbol{f}_{\text {WPD }}$ & $\boldsymbol{f}_{\text {cap }}+\boldsymbol{f}_{\text {power }}+\boldsymbol{f}_{\text {WPD }}$ & $\mathbf{( - )}$ & $\boldsymbol{f}_{\text {cap }}+\boldsymbol{f}_{\text {power }}$ & $\boldsymbol{f}_{\text {WPD }}$ & $\boldsymbol{f}_{\text {cap }}+\boldsymbol{f}_{\text {power }}+\boldsymbol{f}_{\text {WPD }}$ \\
\hline PG15\% $(\mathrm{kWh})$ & 653 & 635 & 633 & 615 & 6561 & 6430 & 6541 & 6410 \\
Difference $(\%)$ & & $-2.8 \%$ & $-3.2 \%$ & $-5.9 \%$ & & $-2.0 \%$ & $-0.3 \%$ & $-2.3 \%$ \\
PG30\% $(\mathrm{kWh})$ & 821 & 762 & 773 & 717 & 6917 & 6561 & 6870 & 6517 \\
Difference $(\%)$ & & $-7.2 \%$ & $-5.9 \%$ & $-12.7 \%$ & & $-5.2 \%$ & $-0.7 \%$ & $-5.8 \%$ \\
\hline
\end{tabular}

As a final test, two $75 \mathrm{~m}$ boreholes are piped in parallel with a total flow rate of $9 \mathrm{gpm}$. Head losses are consequently modified (Figure 6c). As shown in Table 4, this leads to the lowest overall energy consumptions and highest SPF. Using MA15\% requires $5865 \mathrm{kWh}$ with a corresponding SPF of 3.45. Using shorter boreholes in parallel must then be considered as an effective design in terms of energy performance, even if laminar flow occurs in boreholes. Shorter parallel boreholes also lead to higher values of $T_{i n H P}$, min which may decrease the required antifreeze concentration or boreholes length.

\section{CONCLUSION}

The main objective of this paper is to compare the energy consumption of a GCHP system using various antifreeze solutions. It reviews the effects of antifreeze on head losses, borehole thermal resistance and heat pump operation. It also proposes efficiency curves for currently available circulators; a graph estimating required hydraulic power for different flows and pipe diameters; and antifreeze correction factors to correct heat pump capacity, power and head loss. Annual energy simulations are then performed on a residential GCHP system. Results show, as expected, that higher concentrations and higher flow rates increase total energy consumption. Methanol with $15 \%$ concentration and a flow rate of $1.5 \mathrm{gpm} /$ ton gives the lowest annual energy consumption. Ethanol at $30 \%$ and $3 \mathrm{gpm} /$ ton is the worst choice, requiring 16\% more energy and 525\% more pumping power compared to the methanol case. Laminar flow in boreholes appears to be favorable when compared to turbulent flow, which lead to relatively high pumping energy consumption. Finally, placing shorter boreholes in parallel appears to decrease energy consumption and increase the seasonal performance factors. 


\section{ACKNOWLEDGMENTS}

The authors would like to express their sincere gratitude to ASHRAE, Hydro-Quebec and the Natural Sciences and Engineering Research Council of Canada (NSERC) who provided scholarships to the first author. This work was also performed with funds provided by NSERC's Smart Net-Zero Energy Buildings Strategic Research Network.

\section{NOMENCLATURE}

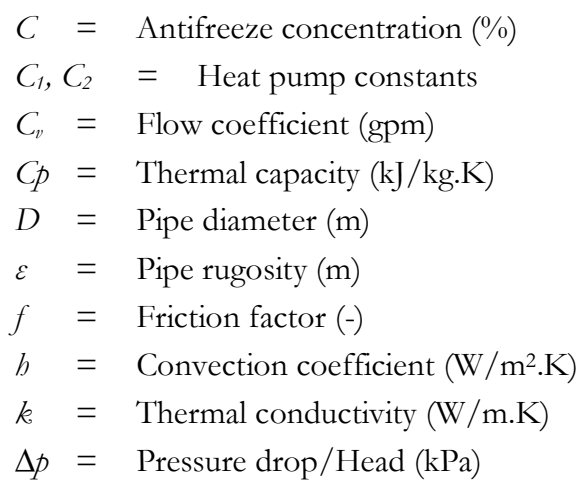

$$
\begin{aligned}
P P & =\text { Power Parameter }\left(\mathrm{gpm}^{3} / \mathrm{in}^{5}\right) \\
\rho & =\text { Density }\left(\mathrm{kg} / \mathrm{m}^{3}\right) \\
Q & =\text { Capacity power }(\mathrm{W}) \\
\mathrm{R} e & =\text { Reynolds number } \\
\mu & =\text { Dynamic viscosity }(\mathrm{kg} / \mathrm{m} . \mathrm{s}) \\
S P F & =\text { Seasonal performance } \\
& \text { factor }(-) \\
V & =\text { Fluid speed }(\mathrm{m} / \mathrm{s}) \\
W & =\text { Power }(\mathrm{W})
\end{aligned}
$$

\section{Subscripts}

$$
\begin{aligned}
& a=\text { Antifreeze mixture } \\
& c a p=\text { Capacity } \\
& c o n v=\text { Convection } \\
& H P=\text { Heat pump } \\
& \text { min }=\text { Minimum } \\
& t=\text { Total } \\
& w=\text { Water } \\
& W P D=\text { Water pressure drop } \\
& \% \mathrm{~m} / \mathrm{m}=\text { Mass Conc. }
\end{aligned}
$$

\section{REFERENCES}

ASHRAE. 2011. Ground Source Heat Pump Systems: Putting the Earth to Work for You (K. Mescher). ASHRAE Webcast Dvd.

Bernier, M., Ladang, O., Hulot, J., Effet du choix du fluide caloporteur sur l'énergie de pompage des systèmes de pompes à chaleur géothermiques, VIIème Colloque Interuniversitaire Franco-Québécois sur la Thermique des Systèmes 23-25 mai 2005, SaintMalo.

Bidstrup, N. 2012. EU Pump Regulations. ASHRAE Journal 54(5): 106-110.

ClimateMaster. 2012. Tranquility 27 (TT) Series Performance Map. USA: ClimateMaster.

COSTIC. 2003. Circulators efficiency based on manufacturers catalogs (Study 24.013). Angers, France: ADEME.

Dow. 2001. Engineering and Operating Guide: DOWFROST Inbibited Propylene Glycol-based Heat Transfer Fluids. USA: Dow Chemical Company.

Gagné-Boisvert, L., and M. Bernier. 2016. Accounting for Borehole Thermal Capacity when Designing Vertical Geothermal Heat Exchangers. Presented at the 2016 ASHRAE Annual Conference, St-Louis, MO, June 25-29.

Gehlin, S.E.A., and J.D. Spitler. (2015). Effects of Ground Heat Exchanger Design Flow Velocities on System Performance of Ground Source Heat Pump Systems in Cold Climates. ASHRAE Meeting.

Godefroy, V., and M. Bernier. 2014. A simple model to account for thermal capacity in boreholes. Proceedings of the 11th IE $A$ Heat Pump Conference, Montreal, Qc, Canada. Paper \#P.4.8.

Godefroy, V., Lecomte, C., Bernier, M., Douglas, M., and M. Armstrong. 2016. Experimental Validation of a Thermal Resistance and Capacity Model for Geothermal Boreholes. ASHRAE Winter Meeting, Orlando, Fl. OR-16-C047.

Grundfos Canada. 2016. Product Center. http://product-selection.grundfos.com. Access on March 14-25 2016.

Heinonen, E.W., M.W. Wildin, A.N. Beall, R.E. Tapscott. (1997). Assessment of antifreeze solutions for ground-source heat pump systems. ASHRAE Transactions, 103(2): 747-756.

Jin, H., and J.D. Spitler. 2003. Parameter estimations based model of water-to-water heat pumps with scroll compressors and water/glycol solutions. Building Serv. Eng. Res. Technol. 24(3): 203-219.

Kavanaugh, S.P., and S.A. McInerny. 2001. Energy Use of Pumping Options for Ground-Source Heat Pumps. ASHRAE Transactions. 107(1): 589-599.

Kavanaugh, S.P. 2011. Less Pumping Means Cooler Ground Loops. ASHRAE Journal 53(7): 26-35.

Kavanaugh, S.P., and J. Kavanaugh. 2012, Long-Term Commercial GSHP Performance Part 2: Ground Loops, Pumps, Ventilation Air and Controls. ASHRAE Journal 54(7): 26-34.

Kavanaugh, S.P., and K. Rafferty. 2015. Ground-Source Heat Pumps: Design of geothermal systems for commercial and institutional buildings. Atlanta, GA: ASHRAE.

Khan, M.H., and J.D. Spitler. 2004. Performance Analysis of a Residential Ground Source Heat Pump System with Antifreeze Solution. Proceedings of SimBuild 2004, Boulder, Colorado August 4-6. 
Klein, S. A. et al. 2010. TRNSYS, a transient simulation program. Solar Energy Laboratory, University of Wisconsin-Madison, USA.

Klein, S. A. et al. 2015. EES: Engineering Equation Solver. Madison, WI: F-Chart Software.

Liu, X., M. Malhotra, P. Im, B. Habibzadeh. 2015. Case studies for GSHP demonstration projects in the US. IE A Heat Pump Center, Newsletter, Vol. 33, No. 3.

Nguyen, A. 2010. Personnal communication about antifreeze correction factors.

Nordman, R., and A. Zottl. 2011. SEPEMO-Build - a European project on seasonal performance factor and monitoring for heat pump systems in the building sector. REHV A Journal 48(4): 56-61.

Salmson. 2016. Product Center. http://selecson.salmson.fr. Access on March 14-25 2016.

White, F.M. 2009. Fluid Mechanics. 7th edition. McGraw-Hill. p.366. 